\title{
Environmental impact assessment of Sundarbans in Bangladesh
}

\author{
Md. Redwanur Rahman \\ Institute of Environmental Science, University of Rajshahi, Rajshahi-6205, Bangladesh \\ Email address: \\ redwan_rahman@1ycos.com
}

To cite this article:

Md. Redwanur Rahman. Environmental Impact Assessment of Sundarbans in Bangladesh. International Journal of Environmental Monitoring and Analysis. Vol. 2, No. 3, 2014, pp. 175-184. doi: 10.11648/j.ijema.20140203.17

\begin{abstract}
The problem of piracy in Sundarbans has been shown as one of the main problems hindering development work therein. In relation to development work of the forest most of the total respondents assigned at various important management positions of the Forest Department (57.14 \% of the officials) mentioned that improving the development work should include measures to protect of Sundarbans from any sort of piracy or robbery. Another problem that chokes the development work of Sundarbans is the inability of the management to forecast properly the weather or other radical environmental phenomenon causing disaster of Sundarbans. After a long survey and study, some logical suggestions have also been made. To protect Sundarbans, all management work should be taken for development and preservation. To do this first of all we need to protect the management staffs that are engaged in the protection of Sundarbans. Then it is expected that the condition of the forest will be improved. Proper community involvement should be made in order to eradicate piracy and other activities detrimental to the Sundarbans, such as indiscriminate felling of trees, and killing of tigers, deer's, and other animals including water resources.
\end{abstract}

Keywords: Environment, Impact, Assessment, Sunderbans, Bangladesh

\section{Introduction}

Different research studies have been carried out in the functional aspects of the Sundarbans. A research paper published on Environmental Concerns, Depleting Resources and Sustainable Development [1]. In 1980, the World Conservation Strategy emphasized the need for conservation of living resources to achieve sustainable development. Another researcher worked on Sundarbans Resource and Ecosystem [2]. An article had published on Integrated Management of Ganges Flood Plains and Sundarbans Ecosystem [3]. Khulna University is located in the resourceful southwestern part of Bangladesh. A group of scientist wrote an article on the Effects of Human Interventions on the Fisheries resources of ganges flood plains and the Sundarbans estuary [4]. An important research entitled on Integrated Resource Development of the Sundarbans Reserved Forest focused by [5]. An article on Status and Potential of Shrimp Farming in Khulna Region wrote by [6]. Diseases and Wood Decay of Tree Species with Particular Reference to Top Dying of Sundriy and the Magnitude of its Damage in the Sundarbans in
Bangladesh had made an article by [7]. [8] Authored an article on Environmental Aspects of Ganges Withdrawal on the Sundarbans Ecosystem. [9] Observed the Mangrove Harvesting and Transportation in Sundarbans. [10] Explained in his paper on Productivity of the Sundarbans is 1.12 cubic metres per hectare per year, which is the lowest among the mangrove forests in the world. [11] Examined in their article on Soil and Water Characteristics in the Eastern part of the Sundarbans. [12] Prepared a research report on Use of Biomass as Cooking Fuel: A Study of a Village Peripheral to the Sundarbans. [13] In their paper had record on Control of Illegal Activities in the Sundarbans: An Overview of the Regulatory Aspects. [14] Introduced a study on Importance of the Sundarbans Mangrove Forest in the Context of Fisheries Resource. [15] Wrote an article on The Sundarbans Fishery at a Glance. [16] Examined on Shrimp Culture around the Sundarbans and its Effects on Land, Agriculture, Livestock and Poultry: A Case Study of Some Selected Villages of Rampal Thana, Bagerhat District. [17] wrote the article on Habitat, Regeneration and Harvesting of Goran (Ceriops decandra) in the Sundarbans Mangrove Forest. [18] In their study on Socio-economic Conditions of the People Depending on the Resources of 
the Sundarbans: A Study of the Impact Zone. [19] made study entitled top dying of Sundri (Heritiera fomes) Trees in the Sundarbans: Extent of Damage. [20] observed their study on The Salinity, Its Distribution and Importance in the Sundarbans Reserved Forest in Bangladesh. [21] Published an article on "Research Needs for the Sustainable management of the Fisheries Resources of the Sundarbans Mangrove Ecosystem. [22] In their study on Problems and Prospects of Development of Tourism Facilities at Katka in the Sundarbans focused that tourism is a rapidly growing activity in third world countries.

The present work has been designed to observing the present environmental impact assessment of Sundarbans.

\section{Methodology}

The EIA of the study area was carried out following the Government of Bangladesh (GOB) approved EIA Guideline, collection of secondary data should be done through literature review. The multi-disciplinary EIA team should visit the area for intensive consultation with the forest expert and stakeholders. The Sundarbans issues of physical as well as environment should be studied through professional observation of the multi-disciplinary EIA team numbers backed up by feedback from the local people during the field visits. The Sundarbans issues should be taken care through secondary information and field observations. Environmental impact should be carried out to collect information on basis of the may be primary and field survey data.

\subsection{EIA Team}

Ten Forest Experts (FE), two Divisional Forest Officers (DFO), four Range Officers (RO), six Forest Rangers (FR), sixteen Deputy Forest Rangers (DFR), eleven Foresters (F), fifteen Forest Guards (FG), and twenty eight Forest Boat Men (FBM) of the Sundarbans forest were interviewed to know causes of forest degradation, weakness of present management and their mitigation in sustainable way.

Thirty-three Forest Wood Cutters (FWC), thirty- five Forest Bawali (FB), thirty Forest Mawali (FM) and thirty five Local People (LP) of the Sundarbans forest around the Sundarbans were interviewed to get the peoples.

\subsection{Environmental Baseline Information in the Study Area}

The environmental baseline condition in the area was prepared based of the Sundarbans investigations, field visits, and consultation with local people. The baseline should include description of Shrimp culture, top dying, wood extraction, and oil spilling from super tank and ship and socio-economic condition including identification of problems in respect of these resources. A series of field visits should be carried in the study area. The main objective of these visits is to identify the Important Environmental and Social Components IECs through a scoping process including scoping sessions. The visits should also aim at discussion with local people as suggested in the EIA guidelines about the Sundarbans. Baseline information includes physico- Chemical, biological and human aspect of the Sundarbans area- i) physico-Chemical: This includes information on land, soil quality, surface water, ground water etc. ii) Biological information includes on terrestrial and aquatic flora and fauna populations and their communities; iii) Human aspects information includes healthy and safety, socioeconomics etc. Additional data were obtained through primary sources which included: a) Field monitoring and b) Field survey.

\subsection{Monitoring Plan}

Monitoring plan should consider the important, the Sundarbans components likely to be impacted by the Forest. The monitoring plan should include suggestions on data to be collected, processed, analyzed and interpreted to detect changes taking place in the impacted area. Location and frequency of data collection on each indicator along with institutional arrangement of environmental monitoring should be suggested in the monitoring plan. The following monitoring measures have been proposed for the sustainable and eco-friendly the Sundarbans and it impact on Environment in the study area. Monitoring plan of the Sundarbans in the study areas are as follows:

\begin{tabular}{ll}
\hline Monitoring Parameters & Monitoring Schedule \\
\hline 1. Water Salinity & Test the water Salinity every month \\
2. Soil Salinity & Test the Soil Salinity every six month \\
3. Top Dying & Test the Top Dying every year \\
4. Oil Pulsation & Test the Oil pulsation every month \\
5. Fish Biodiversity & Test the Fish Biodiversity every month \\
\hline
\end{tabular}

\subsection{Primary Data Collections}

Informal interviews: to assess the Sundarbans situation informal interviews made with relevant person and communities which are affected by developmental activities of the Sundarbans. Site visits: Site visit was helped to identify many of the important environmental components like to be affected by the developmental activities of the Sundarbans. These include soil characteristics, land degradation, land type, vegetation, water regime, quality of life etc.

\section{Results and Discussion}

\subsection{Mitigation Plan in the Study Area}

The negative impacts of the proposed interventions, assessed at the environmental and social impact assessment stage, were picked up for inclusion in the mitigation plan. The mitigation measures are those, which are prescribed to reduce for each of the adverse impact as significant. The 
following mitigation measures have been proposed for the sustainable and eco-friendly the Sundarbans Bangladesh

portion in the study area (Table 1).

Table 1. Environmental Impact Assessment (EIA) of Developmental Activities Impacts on Sundarbans

\begin{tabular}{|c|c|c|c|c|c|c|}
\hline \multirow{2}{*}{ Developmental Activities } & \multicolumn{3}{|c|}{ Positive } & \multicolumn{3}{|c|}{ Negative } \\
\hline & Low & Medium & Highest & Low & Medium & Highest \\
\hline Shrimp Culture & - & - & - & - & Medium & - \\
\hline Top Dying & - & - & - & - & Medium & - \\
\hline Wood Extraction & - & - & - & - & Medium & - \\
\hline Oil Spilling of Ship & _- & _- & _- & Low & _- & _- \\
\hline
\end{tabular}

\subsection{Enhancement Plan in the Sundarbans}

Measures aimed at increasing the benefit of the positive impacts of the proposed interventions was suggested in the enhancement plan. The positive impacts, assessed at the environmental and social impact assessment stage, should be picked up for the enhancement plan. Adverse
Environmental Impacts of wood extract, Shrimp culture, top dying and oil spilling in the Sundarbans and their Mitigation Measures (Table 2, 3, 4 and 5). The following enhancement measures have been proposed for the sustainable and eco-friendly the Sundarbans and it impact on Environment in the study area.

Table 2. Adverse Environmental Impacts of Wood extraction in the Sundarbans and their Mitigation Measures

\begin{tabular}{lll}
\hline Actions Affecting Environment & Potential Environmental Impact & Recommended Mitigation Measures \\
\hline \multirow{2}{*}{ 3. Wood extraction } & i. Destruction of habitats of flora and fauna & $\begin{array}{l}\text { 1. To be protected cutting of trees massively } \\
\text { ii. Loss of biodiversity }\end{array}$ \\
\hline
\end{tabular}

Table 3. Adverse Environmental Impacts of Shrimp culture in the Sundarbans and their Mitigation Measures

\begin{tabular}{|c|c|c|}
\hline $\begin{array}{l}\text { Actions Affecting } \\
\text { Environment }\end{array}$ & Potential Environmental Impact & Recommended Mitigation Measures \\
\hline \multirow[t]{2}{*}{ 1. Shrimp culture } & $\begin{array}{ll}\text { i. } & \text { Changed topography } \\
\text { ii. } & \text { Submergence of adjacent homestead } \\
\text { and garden areas }\end{array}$ & $\begin{array}{l}\text { i. To be used least amount of top soil for dike construction } \\
\text { ii. To be Made dikes wide enough to practice agriculture }\end{array}$ \\
\hline & iii. Contamination of ponds & $\begin{array}{l}\text { iii. To be taken protective measures to prevent entry of saline water } \\
\text { i. To be regulated wild fry collection from natural sources }\end{array}$ \\
\hline 2. Fry collection & i. Reduction of fish biodiversity & $\begin{array}{l}\text { ii. To be motivated only catching of mother shrimp and target fries. } \\
\text { iii. To be established hatcheries for Bagda shrimp culture in the Sundarbans areas } \\
\text { iv. To be ensured quality management of hatchery process } \\
\text { v. Personal training, public education and social services }\end{array}$ \\
\hline \multirow{2}{*}{$\begin{array}{l}\text { 3. Loss of } \\
\text { agricultural land } \\
\text { for shrimp culture }\end{array}$} & $\begin{array}{l}\text { i. Reduction agricultural production } \\
\text { ii. Reduced employment in agriculture } \\
\text { iii. Changed livelihood some of a farmers' } \\
\text { group }\end{array}$ & $\begin{array}{l}\text { i. To be implemented "donation" for shrimp culture } \\
\text { ii. To be used improved Traditional Method of shrimp culture } \\
\text { iii. To be rehabilitated the affected people }\end{array}$ \\
\hline & $\begin{array}{l}\text { iv. Permanent or temporary migration of } \\
\text { some people }\end{array}$ & $\begin{array}{l}\text { iv. To be cultivated salt tolerant crops } \\
\text { v. Schemes for green belt around the affected areas of the Sundarbans }\end{array}$ \\
\hline
\end{tabular}

Table 4. Adverse Environmental Impacts of Top dying in the Sundarbans and their Mitigation Measures

\begin{tabular}{lll}
\hline Actions Affecting Environment & Potential Environmental Impact & Recommended Mitigation Measures \\
\hline & i. Top dying of Sundri trees & \\
& ii. Root rot and resultant die back of Sundri trees & 1. To be elevated freshwater forest \\
2. Top dying & $\begin{array}{l}\text { iii. Sad and heart rot associated with top dying Sundri trees } \\
\text { iv. Massive mortality of Sundri trees due to change in site } \\
\text { condition }\end{array}$ & $\begin{array}{l}\text { 2. To be elevated moderately saltwater } \\
\text { forest }\end{array}$ \\
\hline
\end{tabular}

Table 5. Adverse Environmental Impacts of oil spilling from ship in the Sundarbans and their Mitigation Measures

\begin{tabular}{lll}
\hline $\begin{array}{l}\text { Actions Affecting } \\
\text { Environment }\end{array}$ & Potential Environmental Impact & $\begin{array}{l}\text { Recommended Mitigation } \\
\text { Measures }\end{array}$ \\
\hline \multirow{3}{*}{ 4. Oil spilling from ship } & $\begin{array}{l}\text { 1. Water became oily. } \\
\text { 2. Shrimps and other fishes could not live safely in oily water. } \\
\text { 3. The water areas of the Sundarbans became hazard due to oil spilling from ship }\end{array}$ & $\begin{array}{l}\text { 1. To be protected from the oil } \\
\text { bearer } \\
\text { areas }\end{array}$ \\
\hline
\end{tabular}




\subsection{Forest Expert opinion of the Sundarbans Forest}

Ten Forest Experts (FE) of the Sundarbans Forest to collect information about Environmental Impact Assessment of Development Activities in the Sundarbans.

Most of the Forest Experts (FE) has mentioned the name of the following transportation like-ship or boat and/or vessels, which are, incurred expenses of the forest, in general. Especially, out of ten Forest Experts have mentioned that different types of expenses had incurred damages (such as vessels for traveling by water and fuel (oil) to the forest, and only one has mentioned that communication of ship or boat river way and communication of vessels by river.

Most of the DFO has given suggestion that sustainable management will be ensured if the forest resources and functions are directed according to the management plans and directions. Range officer has said that if management materials are implemented according to the plan, it will ensure sustainable management and also it is possible to sustainable management.

All of the forest rangers have made no comments about sustainable management of Sunderbans. All Deputy Rangers have suggested that it will need a sustainable management plan for protect the Sunderbans.

\subsection{Gher Water (Water within Shrimp Cultivation)}

From south-western part of the coastal saline area 8 water samples were collected under 4 districts. The EC ranges varies from 10.0 to $35.0 \mathrm{dS} / \mathrm{m}$. Highest EC value is observed in Koyra upazila under Khulna district and lowest EC value is observed in Dumuria upazila of Khulna district. All the gher water possesses EC $>10.0 \mathrm{dS} / \mathrm{m}$.

\subsection{Ground water (Shallow and Hand hi in-Well)}

28 water samples were collected from 6 districts in south-west part of the coastal saline and non-saline area. The EC ranges are also very wide varying from 0.39 to $19.8 \mathrm{dS} /$ in. Highest EC value is observed in Shyamnagar upazila of Satkhira district. This water is used for brackish water shrimp cultivation. About $83 \%$ lube well water possesses $\mathrm{EC}<2.0 \mathrm{dS} / \mathrm{m}$ and rest $17 \%$ tub-well water possess $>2.0 \mathrm{dS} / \mathrm{m}$.

\subsection{Ground Water (Deep Tube Well)}

24 water samples were collected from 5 districts in south-west part of the coastal saline and non saline area. The EC range is also very wide varying from 0.55 to 7.8 $\mathrm{dS} / \mathrm{m}$. Highest EC value is observed in Paikgachha upazila of Khulna district. About $50 \%$ tube well water possesses $\mathrm{EC}<2.0 \mathrm{dS} / \mathrm{m}$ and rest $50 \%$ tube well possesses $>2.0$ $\mathrm{dS} / \mathrm{m}$.)

\subsection{Soil Salinity Test Result}

Poor drainage and/or poor irrigation water often contribute to soil salinity. As plants absorb soil water or as water evaporates, salts from the water remain in the soil. For this reason, soil salinity will usually be greater than the salinity of the irrigation water used. Improper irrigation management increases the risk of developing soil salinity. To prevent salt buildup, enough water must be passed through the root zone to leach salts from the soil. Keep in mind that some of these salts are also essential plant nutrients.

\subsection{Present Soil Salinity Status in Coastal Areas}

The present spatial distribution of saline soils was assessed in 2009 through ground survey following reconnaissance soil survey technique using different base materials such as aerial photographs, top-secret, Upazila Soil and Landform map, previous published Soil salinity map etc. Distribution of soils with different degrees of salinity is shown on Soil Salinity map, 2009. Out of about 1.689 million hectares of coastal land about 1.056 million hectares are affected by soil salinity of various degrees. About 0.328, 0.274, 0.189, 0.161 and 0.101 million hectares of land are affected by very slight ( $\mathrm{Si})$, slight (82), moderate (83), strong (84) and very strong salinity (85) respectively. Some of the new land of Satkhira, Patuakhali, Borguna, Barisal, Jhalakathi, Pirojpur, Jessor, Narail, Gopalganj and Madaripur districts are affected by different degrees of salinity, which reduces agricultural productivity remarkably. A comparative study of soil salinity during last four decades (1973-2009) in coastal areas is shown in table 2. About $50 \%$ of the coastal lands face different degrees of inundation, thus limiting their effective use (Table 6). This situation is expected to become worse further because of the effects of climate change. Cropping intensity may be increased in very slight and slightly saline areas by adopting proper soil and water management practices with the introduction of different salt tolerant varieties of crops.

Table 6. A comparative study of the salt affected area between 1975 to 2011 in coastal areas

\begin{tabular}{lllll}
\hline \multicolumn{2}{c}{ Salt affected' area ( $\mathbf{0 0 0}$ 'ha $)$} & & $\begin{array}{l}\text { Salt affected area increased during last } \mathbf{9} \\
\text { years (000'ha) } \mathbf{( 2 0 0 0 - 2 0 1 1 )}\end{array}$ & $\begin{array}{l}\text { Salt affected area increased during last 36 } \\
\text { years (000'ha) } \mathbf{( 1 9 7 5 - 2 0 1 1 )}\end{array}$ \\
\hline 1975 & 2000 & 2011 & $35.51(3.5 \%)$ & $222.81(26.7 \%)$ \\
833.45 & 1020.75 & 1056.26 & & \\
\hline
\end{tabular}




\subsection{Salt Characteristics}

Highest salt accumulation is observed in Ganges tidal floodplain. In this physiographic unit maximum electrical conductivity is recorded as $49.5 \mathrm{dS} / \mathrm{m}$. In topsoil it varies from 0.3 to $70.0 \mathrm{dS} / \mathrm{m}$. The amount of accumulated salt is found higher at the surface horizon. It decreases with depth and then increases again in all the pedons. The highest total soluble salts $(3122 \mathrm{mg} / \mathrm{L})$ are found under brackish water shrimp cultivation. Among the four physiographic units, the amount of accumulated salts preponderance decrease in the order Ganges tidal floodplain > Lower Meghna estuarine floodplain $>$ Ganges river meander floodplain $>$ Peat basin. Electrical conductivity $\left(\mathrm{EC}_{\mathrm{C}}\right)$ of almost all the soils decreases with depth and then increases again due to influence of saline ground water. The higher ECe value at the surface horizon followed by lower value with depth is due to flooding with saline water or accumulation of salts through upward capillary movement of saline ground water. In shrimp cultivated areas, flooding with high saline water for a considerable time in each year causing higher soil salinity in all the horizons.

As salt concentration increases, water becomes increasingly difficult for the plant to absorb. A plant can actually die from water stress or drought in a moist soil if the salt concentration becomes high enough. Other effects of salts on plants are toxicities of specific salts and nutritional imbalances. Some elements, such as sodium, chlorine and boron have specific toxic effects on plants. Plants Sensitive to these elements may be affected at relatively low salt levels in the soil can upset the nutrient balance in the plant or interfere with the uptake of some nutrients

\subsection{Present Cropping Pattern}

Present cropping pattern is mainly determined by the depth, duration and recession time of seasonal flood water, dry season soil salinity and availability of fresh irrigation water in the dry season. During field survey 60 different cropping patterns have been identified in these areas. It is evident that a considerable change in land use during this period has been occurred. During field survey 9 modern transplanted amon and 7 modern boro varieties were identified in the farmer's field. Presently, cropping intensity has increased. Early winter vegetables are intensively cultivated through relay cropping with Transplanted aus along with the cultivation of hybrid cowpeas, hybrid tomato, hybrid khirai, hybrid chilli, hybrid raddish, hybrid watermelon in south east and southern part, particularly in Cox's Bazar sadar, Chakaria, Maheshkhali and Kalapara upazillas. Among several production problems, soil salinity in the major constraints. The problem is particularly acute in those areas where soil salinity is relatively high. Moreover, most of the vegetable crops are said to be very sensitive to saline condition and their yield decreased from $6-19 \%$ with each unit increase in salinity. Due to high soil and water salinity cropping intensity reduced considerably.
Farmer's ignorance and less imitativeness are also partly responsible for less cropping intensity in this region. Mapping unit wise major present cropping pattern with area is shown. The main reason of changing crops/cropping patterns are: Climatic variability, Increased salinity and tidal surges, Increasing demand of early winter vegetables in the market, Increased demand of cash/high value crop, Changed/increased demand of food grains, Intrusions of saline water/pushing saline water in confined areas (Gher areas) for brackish water shrimp cultivation and Introduction of salt tolerant rice varieties.

\subsection{Plant Responses}

Plants vary in their response to soil salinity. Salt tolerant plants arc better able to adjust internally to the osmotic effects of high salt concentrations than salt sensitive plants. Salt-tolerant plants are more able to absorb water from saline soils. Salt sensitive plants have a limited ability to adjust and are injured at relatively low salt concentrations. Many horticultural and landscape (field) plants are classified as sensitive or moderately sensitive to soil salinity. The plants listed are offered as representative of a salt tolerance group. The plants listed can be used to determine the salt tolerance of closely related plants or plants adapted to similar sites. The tolerance rating in is to be interpreted only as a guide in making comparisons among plants and supply generally from late seedling stage to maturity.

Specific plant tolerances are affected by climate (rainfall and temperature), soil conditions, cultural practices, and variety selection. During cool and wet weather when plant transpiration demands are low and leaching is much higher than capillary upward movement, salt injury will be less than during hot, dry weather. There is a wide variation in salt tolerance among varieties or root stocks of some species.

\subsection{Effect of Salinity on Growth, Development and Yield on Vegetables}

The general effect of soil salinity on plants is called an osmotic effect. This means that salts increase the energy with which water is held in the soil. In other words, the soil must be kept wetter to supply the same amount of plantavailable water as would be present within the salts. Plants then must increase the energy they expand to obtain water from the soil. They must use energy to get water that would otherwise be used for growth, flowering, or fruiting. When the soil salinity exceeds a plant's tolerance, growth reductions occur. Salinity tolerance of a crop not only varies among crops/varieties but depends upon environment and cultural practices also. Therefore, to have more realistic assessment of salinity tolerance of a given crop, the value of soil salinity at which initial yield decline begins and percentage yield decline with per unit increase in salinity in given in Table 7 for different vegetable crops only. 
Table 7. Soil salinity $(\mathrm{dS} / \mathrm{m})$ at which initial yield decline begins and percent (\%) yield increase in salinity

\begin{tabular}{lll}
\hline $\begin{array}{l}\text { Name of the } \\
\text { Crop }\end{array}$ & $\begin{array}{l}\text { Soil salinity at which } \\
\text { initial yield decline } \\
\text { begins }\end{array}$ & $\begin{array}{l}\text { Percent yield decline } \\
\text { with per unit increase in } \\
\text { salinity }\end{array}$ \\
\hline Bean & 1.0 & 19.0 \\
Broad bean & 1.6 & 9.6 \\
Broccoli & 2.8 & 9.2 \\
Cabbage & 1.8 & 6.2 \\
Carrot & 1.0 & 14.0 \\
Celery & 1.8 & 6.2 \\
Cucumber & 2.5 & 13.0 \\
Lettuce & 1.3 & 13.0 \\
Onion & 1.2 & 16.0 \\
Pepper & 1.5 & 14.0 \\
Potato & 1.7 & 12.0 \\
Radish & 1.2 & 13.0 \\
Spinach & 2.0 & 7.6 \\
Sweet corn & 1.7 & 12.0 \\
Squash & 3.2 & 16.0 \\
Tomato & 2.5 & 9.9 \\
Turnip & 0.9 & 9.0 \\
\hline
\end{tabular}

Source: Technical Bulletin-1, Hisar Agricultural University

\subsection{Induction to Salt Tolerance}

Several methods like prolonged cultivation in increasingly saline soils, presuming soaking treatment in salt, growth substance, micronutrients and other chemicals, spraying with various regulator solutions, dipping the intact flowering or fruiting branches in salt solution and grafting on salt tolerant root stocks have been used to induce salt tolerance in different crops (Technical Bulletin-1). Very little efforts have been made on different crops including vegetables in this connection in Bangladesh. Some successful efforts have been made in case of onion, tomato, okra, cauliflower and potato crops in different countries and the results are summarized (Table 8).

Table 8. Salt tolerance induction in some vegetable crops

\begin{tabular}{lllll}
\hline Name of the crop & $\begin{array}{l}\text { Name of the chemical/growth } \\
\text { substance }\end{array}$ & Concentration & Method of treatment & $\begin{array}{l}\text { Time for treatment } \\
\text { (Hours) }\end{array}$ \\
\hline Cauliflower & Cycocel & $250 \mathrm{ppm}$ & Root dipping for transplants & 2.0 \\
Okra & Cycocel & $500 \mathrm{ppm}$ & Seed soaking & 6.0 \\
Onion & Cycocel & $1.0 \%$ & Root dipping for transplants & 8.0 \\
Potato & Sodium salt solution or Cycocel & $6.0 \mathrm{dS} / \mathrm{m} \mathrm{EC}$ or $25 \mathrm{Oppm}$ & Tuber soaking & 2.0 \\
Tomato & Sodium salt solution & $8.0 \mathrm{dS} / \mathrm{m} \mathrm{EC}$ & Root dipping for transplants & 2.0 \\
\hline
\end{tabular}

Source: Technical Bulletin-I, Hisar Agricultural University

\subsection{Major Agricultural Constraints}

Higher cropping intensity is observed in mapping unit 1 to 3 . In mapping unit 4 and 5 it is considerably less due to higher soil and water salinity in dry season. Several agricultural constraints are identified in coastal saline areas. The dominant soil, land and water related constraints are: Strong to very strong soil salinity, Limited scope of ground water and river water enlistment for irrigation, Severe scarcity of quality irrigation water during dry season, Late draining condition in early dry season in considerable areas, Prolonged artificial water logging with saline water for aquaculture, Cyclone and tidal bore, Heavy soil consistency, Presence of toxic potential acid sulphate soil in some areas, Relatively high flooding depth during monsoon season for HYV transplanted amen crop, Presence of peat soils having low bearing capacity and very late draining condition. Mapping unit wise major constraints on agricultural productivity is presented below in Table 9 .

\subsection{Prevalence of Top Dying of Sundri}

In the Sundarbans there are 9 blocks having 55 compartments. Top dying has been found to prevail in all the nine blocks in the Sundarbans. According to the inventory conducted by ODA in $1983 / 84$, out of 55 compartments in the Sundarbans, in 14 compartments (viz. $6,14,21,23,25,26,28,32,33,38,39,45,46$ and 47), top dying of sundri were found to be severe.

By 1991-92 severe top dying of sundri damage was prevalent in other compartments (viz 19, 20, $36 \& 37$ ) as well. Moderate top dying has been seen to be prevailing in compartments $17,18,31,35,40 \& 42$. Thus an increasing build up of top dying has warranted salvage extraction of top dying sundri in the Sundarbans by the Forest Department which was started during 1990-91 and by 1991-92 it was completed in compartments 32, 36, 37 and 3E. By 1993-94 salvage extraction of top dying sundri was completed in compartments 20 and 39 as well. In still other cases, top dying trees are seen to develop very reduced, deformed and bronze color leaves of very little photosynthetic potential. With the development of such moribund leaves, such trees seem to be degenerating at a fast rate. This sort of symptoms is seen in areas where most of the pneumatophores have been buried partially in such sites massive death of trees occurs. 
Table 9. Major agricultural constraints

\begin{tabular}{|c|c|}
\hline Mapping unit on & Major agricultural constraints on agricultural productivity \\
\hline 1 Non saline with some very slightly saline & $\begin{array}{l}\text { - } \quad \text { Very slight to slight soil salinity. } \\
\text { - } \quad \text { Perennial water logging due to inadequate drainage facilities. }\end{array}$ \\
\hline 2 Very slightly saline with some slightly saline & $\begin{array}{l}\text { - } \quad \text { Very slight to moderate soil salinity. } \\
\text { - } \quad \text { Scarcity of quality irrigation water during dry season. } \\
\text { - } \quad \text { Moderately deep flooding in monsoon season and risk of flush flood. } \\
\text { - } \quad \text { Perennial water logging due to inadequate drainage facilities. }\end{array}$ \\
\hline 3 Slightly saline with some moderately saline & $\begin{array}{l}\text { - } \quad \text { Very slight to strong soil salinity. } \\
\text { - } \quad \text { Scarcity of quality irrigation water during dry season. } \\
\text { - } \quad \text { Peren of ground and river water enlistment for irrigation is limited. } \\
\text { - } \quad \text { Prolonged artificial water logging with saline water for aquaculture. } \\
\text { - } \quad \text { Existence of toxic buried potential acid sulphate layer. }\end{array}$ \\
\hline $\begin{array}{l}4 \text { \& } 5 \text { Strongly saline with some moderately saline } \\
\text { \& Very strongly saline with some strongly saline }\end{array}$ & $\begin{array}{l}\text { - } \quad \text { Slight to very strong soil salinity. } \\
\text { - } \quad \text { Severe scarcity of quality irrigation water during dry season. } \\
\text { - } \quad \text { No scope of ground and river water enlistment for irrigation. } \\
\text { - } \quad \text { Existence of toxic potential acid sulphate soil. } \\
\text { Cyclone and tidal bore. }\end{array}$ \\
\hline
\end{tabular}

Sundri affected by top dying are sometimes heavily colonized by a fern Drynana quercifoha by mistletoe, Dendrophthoe falcate, or by an orchid Sarcanthus appendiculatus, but the incidence of these are not sufficiently abundant or consistent to suggest that they are of a primary consideration as a cause of the disorder.

In general, a higher incidence of top dying occurs in the mixed gewa-sundri forest type than in the other forest types in which sundri is a major component. On the contrary, in majority of the blocks, top dying of sundri is absent in the sundri-passur and sundri-kankra forest types The influence of different association of sundri on the incidence of top dying need further study.

\subsection{Extent of Death of Main Stem in Top Dying Sundri}

At Jaliakhal, in compartment 20, one of the sites was seen to be severely affected by top dying. In that site there has been a lot of siltation as evidenced by virtual burial of the pneumatophores of most of the trees. This was particularly true in case of sundri. In that site most of the sundri have either died or are in the process of dying. But at a short distance from the site on the other site of Jaliakhai there were apparently healthy sundri and stand having scattered top dead trees. It was, therefore, considered useful to assess the extent of death of main stems because of top dying in the severely affected area and that of a scattered top dying area. Another site of top dying area was found at PSP 56 on the west bank of Hangshowraj River in compartment 20. On all these three sites sundri trees were randomly examined, and in case of a top dying tree the extent of death of the main stem was visually estimated and then percent of the main stem still healthy and the portion affected by top dying (including portion already broken) was estimated and recorded for individual tree. To compare these data, actual measurement were taken of healthy portion and top dead 'portion of the main stem of 18 ' felled sundri trees at Gewakh top dying Felling Coupe during the present study In late 2009.

The results show that on the two top dying sites $0110 \%$ and $8331 \%$ of the main stem were found to still remain healthy and capable of producing saw logs while the remaining portions were dead and/or truncated This visual estimation was in good agreement with the data obtained from actual measurement in which case $20 \%$ of the main stem was found to have healthy wood and the remaining 21 $80 \%$ had dead stem In the case of the worst top dying affected site $4611 \%$ of the main stem had healthy wood while the remaining $5389 \%$ of the stem had already dead top This mean value of 53.89 is highly significantly greater $(\mathrm{P}=0.001)$ than the remaining three mean values obtained from top dying areas. It thus, suggests that the most severely affected site had separate factors which have really aggravated the severity of top dying as compared to other sites having scattered top dying.

\subsection{Loss of Wood Quality Associated with Top Dying of Sundri}

Forest Department's Sundri lop Dying Felling and Marking Registers were examined for compartments 32, 36, 37,38 and 39. For each compartment, records from each of 25 trees, which yielded at least one saw log and had a minimum top inner bark diameter of $10 \mathrm{~cm}$, were randomly selected from the records. This provided an estimate of potential tree volume. The volume and proportion of 
decayed wood was estimated for each tree by subtracting the sound volume recovered per tree as recorded in the marking and felling registers from the calculated potential volume.

Results of this study with 25 felled sundri threes from each of compartments $32,36,37,38$ and 39 indicate that an average of $42.72 \%$ (Range $31.91-43.67 \%$ ) of the total wood volume recovered from these trees is degraded and become unsuitable for lumber production. Such wood is used only for production of hardboard. On an average $49.33 \%$ (range $41.35 \%$ to $62.14 \%$ ) wood provided saw logs and $7.95 \%$ wood was lost due to buck cut and undercut.

\subsection{Extent and Occurrence of Dead Trees among Top Dying Sundri}

An analysis of Forest Department's Sundri Top Dying Marking and Felling Registers was made to estimate the proportion of totally dead trees which were harvested. Records from Compartments 20, 32, 36, 37, 38 and 39 were examined. These produced a total of 85525 individual tree records. These records indicate that the proportion of totally dead trees harvested in the compartments averaged 15.69\% and ranged froml.59\% to $37.85 \%$.

\subsection{Overall Yields of Sound and Degraded Wood from Areas Affected by Top dying of Sundri in the sundarbans}

The number of dead trees harvested in each compartment was taken directly from Forest Department's Sundri Top Dying Marking and Felling Registers. Counts of the number of totally dead trees harvested and their $\mathrm{d} \mathrm{b} \mathrm{h}$ and height were available but not their volume. Volume of each totally dead tree harvested was estimated from sundri tree volume regression curves (Chaffy et al., 1985) and corrected for volume loss due to under cutting and bucking (Larsen, 2009) the entire volume of these trees was considered to be degraded and useable only for hardboard. Sound volume of each top dying tree harvested in these compartments was obtained directly from the above marking and felling registers.

It has been estimated that a total of $4262.18 \mathrm{~m}$ wood was obtainable from 22518 dying sundri trees felled in four compartments (viz. 32, 36, 37 and 38). Of this total, only $1803.60 \mathrm{~m}$ or $42.32 \%$ was estimated to be sound and suitable for lumber production, $1571.21 \mathrm{~m}$ or $36.86 \%$ was direct top dying degrade and the remaining $887.30 \mathrm{~m}$ $20.82 \%$ resulted from dead trees badly decayed (more commonly in the sapwood and rarely in the heartwood). Such wood is not suitable for lumber production and is used for making hardboard only. Thus overall degradation for the wood was $57.68 \%$ while $\log$ production amounted to $42.32 \%$ of the total volume of $4262.36 \mathrm{~m}^{3}$.

\subsection{Indiscriminate Killing of Wild Fish Seed}

In the absence of adequate number of functional hatcheries and with the rapid expansion of shrimp farming, the collection of wild tiger shrimp post larvae from Sundarbans/estuaries and near shore waters has tremendously increased leading to destruction of shrimp and other fin fish species. It is seen from a report of FRI that by collection of one PL of Pena us monsoon, 40 other shrimp and 10 other fin fish larvae are killed which leads to serious depletion of natural population of both shrimp and fin fish, particularly in the near shore areas.

\subsection{Imbalance in Coastal Ecology}

Unplanned growth of shrimp culture in coastal areas of Khulna, Satkhira and Bagerhat districts has a serious effect on alteration of coastal ecology. Vast area of tidal land previously used for rice cultivation in Khulna and Bagerhat districts has been changed in to shrimp farm. Inundation of arable lands by saline water to cultivate shrimp has become a common occurrence.

A large number of people both male and female including children are getting increasingly engaged in fry collection.

\subsection{Address Effect on Biodiversity}

About 12 fish species are considered as endangered/threatened due to their gradual disappearance as a result of change or conversion of habitat and degradation of environment.

Although, try collection from the wild presently provides some employment, this is not significant compared to the loss it results in the form of ecological alteration, environmental degradation and change in natural balance in fish population.

In order to reduce the impact of shrimp fry collection, the Government is planning to expand its support to establish hatchery in the private sector. Establishment of shrimp estate for the private hatchery, construction of required infrastructural facilities for shrimp farm and hatcheries under private entrepreneur etc. are included in the Govt. plan. The plan also includes demarcation of land considering its suitability for shrimp farming and the management method like semi-intensive and improved traditional to be used in particular area.

\subsection{Impact of Shrimp Farm Discharge}

The semi-intensive and intensive system employs occasional water exchange. Intensive culture system which is now in a take-off stage utilizes some pond preparation, water quality management, supplementary feeding, aeration and regular water exchange. Although noticeable environmental problems have not been observed, yet signs of increased salinity in the enclosure where the same land was used for paddy cultivation, and deposition of organic matter and nutrients are there

Proper engineering design of the pond and farm is necessary Nutrient sink' concept has to be adopted to utilize the effluent from the farm. 


\subsection{Impact of Land Use Pattern for Shrimp Farming}

High rate of economic return in shrimp farming is constantly inducing the farmers to convert more and more paddy field into shrimp farm. This has resulted in over exploitation of shrimp juvenile from the wild leading to ecological imbalance, change in cropping pattern, interest conflict, leasing of land of small farmers, depriving them of their rights to own land and other socio-economic and environmental consequences.

\subsection{Impact of Aquaculture on Environment}

Destruction of mangrove is of great consequence because shrimp farms are constructed by clearing mangrove. This also results into shrinking of grazing land and destruction of inland forest. Horizontal expansion of traditional extensive shrimp farming reduce grazing land and affect the fruit bearing trees like mango, rose apple, betel nut and coconut due to prolong retention of saline water Production of crops and green vegetables has alarmingly fallen down due to increased salinity.

Shrimp growers indiscriminately cut the embankments at several points and also open the sluice gates frequently for intrusion of saline water inside the embankment causing harm to the standing crops. However, minimum salinity is not detrimental to land fertility. It becomes hazardous when it exceeds the minimum level. The salinity level in the coastal lands has presently increased manifolds than the minimum level.

The farmers should cultivate shrimps in scientific manner to obtain higher production and at the same time protect environment. Unavailability of hatchery produced shrimp on the one hand and expansion of shrimp culture in the coastal area on the other increased pressure on the collection of wild shrimp fry.

\section{Conclusions}

It is suggested that in the management system the recommended management plan should be introduced. The existing plan needs a correction. The preservation of forest can be done through selection cutting method. Participation of the local people would be very essential in that case. Finally, for a sustainable management of the Sundarbans forest appropriate participation of the local people, administration, law enforcement agency and the government is very vital.

\section{References}

[1] V.S. Katiyar, "Environmental Concerns, Depleting Resources and Sustainable Development" Pointer Publishers, Jaipur, India, 1993, p.28.

[2] S.S. Ali, "Sundarbans: Its Resources and Ecosystem" Proceeding of the National Seminar on Integrated Management of Ganges Flood Plains and Sundarbans Ecosystem, Khulna University, 1994, p.38.
[3] M.G.A Fakir and M.A. Islam, "Strengthening social forestry in Khulna region.Proceeding of the National Seminar on Integrated Management of Ganges Flood Plains and Sundarbans Ecosystem", Khulna University, 1994, p.33.

[4] M.A Islam, S. Awal, M.S. Rahman, and M.A.H. Miah, "The Effects of Human Interventions on the Fisheries Resource of Ganges Flood Plains and the Sundarbans Estuary" Proceeding of the National Seminar on Integrated Management of Ganges Flood Plains and Sundarbans Ecosystem, Khulna University, 1994, p.112.

[5] J. Leech, 1994 "Integrated Resource Development of the Sundarbans Reserved Forest", United Nations Development Programme, 1994, pp.51-53.

[6] M.A. Mazid, "Status and Potential of Shrimp Farming in Khulna Region" Proceeding of the National Seminar on Integrated Management of Ganges Flood Plains and Sundarbans Ecosystem, Khulna University, 1994, p.133.

[7] M.A. Rahman, "Diseases and Wood decay of tree species with particular reference to top dying of sundriy and the magnitude of its damage in the Sundarbans in Bangladesh". Proceeding of the National Seminar on Integrated Management of Ganges Flood Plains and Sundarbans Ecosystem, Khulna University, 1994, p.50.

[8] B.N. Kabir, "Environmental Aspects of Ganges withdrawal on the Sundarbans Ecosystem, Proceeding of the National Seminar on Integrated Management of Ganges Flood Plains and Sundarbas Ecosystem" Khulna University, 1994, p.12.

[9] R.S. Larsen, "Mangrove Harvesting and Transportation in Sundarbans" Field Document 2, p. 13.

[10] S.I. Chowdhury, "Productivity of the Sundarbans, State of Sundarbans" Forum of Environmental Journalists of Bangladesh (FEJB), 1998, p.137.

[11] M., Ahsan, M.R., Bhuiyan, S.N. Biswas, and S.T. Kumar, "Soil and Water Characteristics in the Eastern Part of the Sundarbans" Proceeding of the National Seminar on the Suderbans, the Largest Mangrove Forest on the Earth: A World Heritagesite, Khulna University, 2003 p.144.

[12] A.K., Azad, M.M., Bahar, M.N. Uddin, and Z. Sultana, "Use of Biomassas Cooking Fuel: A Study of a Village Peripheral to the Sundarbans" Proceeding of the National Seminar on The Sudarbans, The Largest Mangrove Forest on the Earth: A World Heritagesite, Khulna University, 2003, p. 54.

[13] M.U. Ahmed and F. Ahmed, "Control of Illegal Activities in the Sundarbans: An Overview of the Regulatory Aspect" Proceeding of the National Seminar on The Suderbans, The Largest Mangrove Forest on the Earth: A World Heritage site, Khulna University, 2003, p.83.

[14] K.A. Huq, and A.M.H. Tareque, "Importance of the Sundarbans Mangrove Forest in the Context of Fisheries Resource" Proceeding of the National Seminar on the Suderbans, the Largest Mangrove Forest on the Earth: A World Heritagesite, Khulna University, and 2003, p.32.

[15] A. Khan, and M.A. Rouf, "The Sundarbans Fishery at a Glance, Proceeding of the National Seminar on the Suderbans, the Largest Mangrove Forest on the Earth: A World Heritagesite" Khulna University, 2003, p. 1. 
[16] M.R. Karim, and K.S. Islam, "Shrimp Culture around the Sundarbans and its Effects on Land, Agriculture, Livestock and Poultry: A Case Study of Some Selected Villages of Rampal Thana, Bagerhat Distric" Proceeding of the National Seminar on The Suderbans, The Largest Mangrove Forest on the Earth: A World Heritagesite, Khulna University, 2003, p.18.

[17] M.A. Matin, M.S. Islam and M.N. Sadath, "Haabitat, Regeneration and Harvesting of Goran (Ceriops decandra) in the Sundarbans Mangrove Forest" Proceeding of the National Seminar on The Suderbans, The Largest Mangrove Forest on the Earth: A World Heritagesite, Khulna University, 2003, p.161.

[18] M.G. Murtaza, S.J. Ahmed and K.M. Nahiduzzaman, "Socio-Economic Conditions of the People Depending on the Resources of the Sundarbans: A Study of the Impact Zon", Proceeding of the National Seminar on the Suderbans, the Largest Mangrove Forest on the Earth: A World Heritagesite, Khulna University, 2003, p.88.

[19] M.A. Rahman, "Top Dying of Sundri (Heritiera fomes)
Trees in the Sundarbans: Extent of Damage", Proceeding of the National Seminar on The Suderbans, The Largest Mangrove Forest on the Earth: A World Heritagesite, Khulna University, 2003, p.1.

[20] M.S. Rahman, M.S. Shah and M. Hasan, "The Salinity, Its Distribution and Importance in the Sundarbans Reserved Forest in Bangladesh". Proceeding of the National Seminar on the suderbans the Largest Mangrove Forest on the Earth: AWorld Heritagesite, Khulna University, 2003, p.25.

[21] S.M. Sazzad, K.R. Rahaman and M.M. Saroar, "Problems and Prospects of Development of Tourism Facilities at Katkain the Sundarbans" Proceeding of the National Seminar on the Suderbans, the Largest Mangrove Forest on the Earth: A World Heritagesite, Khulna University, 2003, p.72.

[22] M.S. Shah, "Research Needs for the Sustainable Management of the Fisheries Resources of the Sundarbans Mangrove Ecosystem" Proceeding of the National Seminar on The Suderbans, The Largest Mangrove Forest on the Earth: A World Heritagesite, Khulna University, 2003, p.153. 